\title{
基于焅理论的 $\mathbf{H}$ 形多尺度换热器构形优化
}

\author{
冯辉君，陈林根 ${ }^{*}$, 谢志辉, 孙丰瑞 \\ 海军工程大学动力工程学院, 武汉 430033 \\ *E-mail: lingenchen@ hotmail.com \\ 收稿日期: 2012-07-27; 接受日期: 2012-11-23 \\ 国家自然科学基金(批准号: 51176203)和海军工程大学青年基金(批准号: HGDQNJJ11008)资助项目
}

\begin{abstract}
摘要与换热器热有效性定义类比, 定义换热器的焒耗散有效性为无量纲䛈耗散率与无 量纲总原功率之比. 以焒耗散有效性最大为优化目标, 分别在换热器管道总体积和总表面 积一定的约束条件下, 对 $\mathrm{H}$ 形多尺度换热器进行构形优化, 得到㒭耗散有效性最大时的 $\mathrm{H}$ 形多尺度换热器最优构形. 结果表明在换热器管道总体积一定的条件下, 对于一级 $\mathrm{T}$ 形换 热器, 当冷、热流体质量流率较小时, 热有效性和猰耗散有效性最大的一级 $\mathrm{T}$ 形换热器最 优构形是明显不同的. 对于 $\mathrm{H}$ 形多尺度换热器, 给定换热器级数时, 倁耗散有效性随质量 流率的增大而减小; 给定无量纲质量流率 $M(M<32.9)$ 时, 政耗散有效性随换热器级数的增 加而减小. $\mathrm{H}$ 形多尺度换热器与 $\mathrm{H}$ 形单尺度换热器相比, 多尺度换热器性能得到显著提高. 此外, 本文还对换热器管道表面积约束的情形进行了讨论. 本文优化结果使得换热器的传 热和流动性能得到很好的兼顾, 可为换热器的优化设计提供参考, 有助于丰富焒理论内涵.
\end{abstract}

\section{关键词}

构形理论

热有效性

㹸耗散有效性

$\mathrm{H}$ 形多尺度换热器

广义热力学优化

\section{1 前言}

换热器作为一类重要的热工设备, 在钢铁、化 工、能源、电力、航空等领域均有广泛应用. 因此, 换热器的优化设计对各工业领域能源利用率的提高 具有重要意义. 一些学者以熵产生最小为优化目标 对换热器性能进行了分析和优化 ${ }^{[1 ~ 5]}$, 但在其优化设 计中出现了换热器熵产最小与其效能最大并不对应 的“商产悖论”, [1,2]. 针对“熵产悖论”这一问题, 一些 学者基于熵产定义了各种修正目标试图解决这一悖 论 $^{[\sigma \sim 11]}$.

为了反映传热的本质属性, 过增元等人 ${ }^{[12,13]}$ 提 出了新的物理量“炾” (文献[14]曾称之为热量传递势 容)和新的传热优化理论依据和评判标准“聟耗散极
值原理”, 基于积耗散定义了多维导热问题中反映平 均散热性能的当量热阻, 并从导热机理、电热模拟试 验等角度 ${ }^{[15 \sim 17]}$ 对积的物理意义作了进一步地阐述. 此后, 许多学者在积理论的指导下开展了一系列的传 热优化工作 ${ }^{[18 \sim 56]}$, 其中文献[19 41] 是积理论与换热 器优化结合的典范, 文献[42 56]是积理论与构形优 化结合的代表之作. 在换热器的分析和优化设计中, 柳雄斌等人 ${ }^{[19,20]}$ 和过增元等人 ${ }^{[21]}$ 基于积耗散定义了 换热器当量热阻, 并基于这一热阻对换热器的性能 进行了分析. 宋伟明等人 ${ }^{[22]}$ 和夏少军等人 ${ }^{[23]}$ 验证了 换热系数固定时的换热器温差场均匀性原则, 郭江 峰等人 ${ }^{[24,25]}$ 进一步讨论了换热系数固定和不固定时 欵耗散均匀分布原则和温差均匀分布原则的关系. 柳




别基于熵产理论和欵耗散理论对各种换热器性能进 行了分析和比较, 发现基于倁耗散理论的换热器优化 设计更具适应性. 郭江峰等人 ${ }^{[29,30]}$ 和李孟寻等人 ${ }^{[31]}$ 研究了椥耗散数在换热器优化设计中的应用, 文献 [32 36]分别对换热器组和换热器网络进行了优化. 许明田等人 ${ }^{[37]}$ 导出了换热器中由流体阻力引起的倁 耗散表达式, 李雪芳等人 ${ }^{[38]}$ 同时考虑了换热器有限 温差传热和黏性流体引起的䍉耗散, 郭江峰等人 ${ }^{[39,40]}$ 分析了流体黏度固定和不固定时黏性热效应对两流 体换热器性能的影响. 郭江峰等人 ${ }^{[41]}$ 在换热器性能 优化时发现传热䍉耗散数比流体阻力䍉耗散数大了 近三个数量级, 流体阻力作用在优化过程被忽略, 并 采用了多目标优化克服了这一缺点.

以上研究工作大多是换热器管道为单一尺度的 换热器分析和优化, 一些学者基于构形理论 ${ }^{[57 ~ 64]}$ 对 管道为多尺度的换热器 ${ }^{[65 ~ 67]}$ 开展了研究. da Silva 等 人 $^{[65]}$ 对换热器管径比服从 Murry 定律的逆流式 H 形 多尺度换热器进行了构形设计, 对换热器换热和流 动性能进行了分析, 得到了换热器热阻和原功率的 单调递减函数关系. Zimparov 等人 ${ }^{[6]}$ 对顺流式和逆 流式多尺度树形换热器性能进行了比较, 结果表明 在较高的洜功率下, 逆流式树形换热器性能优于顺 流式树形换热器性能. da Silva 等人 ${ }^{[67]}$ 进一步对逆流 式树形换热器开展了实验研究. 此外, 陈永平等人 ${ }^{[68 \sim 71]}$ 分析了分形树状通道换热器的热有效性(换热量 与总原功的比值), 使得分形树状通道换热器换热量 和泵功得到兼顾, 并发现树状换热器的热有效性明 显高于传统平行通道换热器的热有效性.

在换热器性能优化中, 传热䍉耗散和流体阻力 积耗散相加时, 流动阻力因素容易被“湮没”, 从而导 致较大的泵功消耗 ${ }^{[41]}$. 基于这一考虑, 本文将类比文 献[68 71]中热有效性的定义, 定义换热器椥耗散有 效性为无量纲传热倁耗散率与无量纲总百功率之比. 䍉耗散有效性目标能够有效地克服流体阻力因素在 优化过程被忽略的缺点, 使得换热器传热和流动性 能在优化中得到较好的兼顾, 体现了传热䍉耗散率与 总百功率性能优化的折衷. 本文将在文献[65]的基础 上, 以沵耗散有效性最大为优化目标, 对 $\mathrm{H}$ 形多尺度 换热器进行构形优化, 得到兼顾换热器传热和流动 性能的 $\mathrm{H}$ 形多尺度换热器最优构形, 并与 $\mathrm{H}$ 形单尺 度换热器和最大热有效性的 $\mathrm{H}$ 形多尺度换热器性能 进行比较.

\section{2 熕耗散的定义 ${ }^{[12]}$}

文献[12]中定义了一物体所具有的热量传递的 总能力——物理量积 $\left(E_{v h}\right)$

$$
E_{v h}=\frac{1}{2} Q_{v h} U_{h}=\frac{1}{2} Q_{v h} T,
$$

其中 $Q_{v h}=M c_{v} T$ 为物体的定容热容量, $U_{h}$ 或 $T$ 是温度, 即热势. 由此得到了单位时间单位体积内倁的耗散, 称为积耗散函数 $\dot{E}_{h \phi}$

$$
\dot{E}_{h \phi}=-\dot{q} \nabla T=k(\nabla T)^{2},
$$

其中 $\dot{q}$ 为热流密度矢量, $\nabla T$ 是温度梯度.

整个控制体体积中的积耗散率 $\dot{E}_{v h \phi}$ 为

$$
\dot{E}_{v h \phi}=\int_{v} \dot{E}_{h \phi} \mathrm{d} v=\int_{v}|\dot{q} \nabla T| \mathrm{d} v,
$$

式中, $v$ 为控制体的体积.

对于换热器性能优化问题, 在给定换热器换热 量边界条件时, 积耗散最小时换热器性能最优; 给定 换热器冷、热流体进口温度边界条件时, 椥耗散最大 时换热器性能最优.

\section{3 一级 $\mathbf{T}$ 形多尺度换热器构形优化}

如图 1 所示 ${ }^{[65]}$, 在矩形区域 $A\left(=4 L_{0} \times 2 L_{1}\right)$ 内, $\mathrm{T}$ 形 逆流式换热器上部分由一根直径为 $D_{1}$ 、长度为 $L_{1}$ 和 二根直径为 $D_{0}$ 、长度为 $L_{0}$ 的管道组成. 高温流体 (质 量流率 $\dot{m}_{1}=\dot{m}$ 、入口温度 $T_{h, \text { in }}$ 从 $D_{1}$ 管道入口处进入, 最后从位于单元体中心的 $D_{0}$ 管道末端流出(质量流率 $\dot{m}_{0}=\dot{m}_{1} / 2$ ). $\mathrm{T}$ 形换热器下部分结构与上部分结构完 全一样, 低温流体 (与高温流体为同一种流体)从位于 单元体中心的 $D_{0}$ 管道入口处进入(质量流率 $\dot{m}_{0}$ 和入 口温度 $T_{c, \text { in }}$ ), 最后从 $D_{1}$ 管道末端流出(质量流率 $\dot{m}_{1}$ ). 高、低温侧流体通过两侧管道壁面进行热量交换, 高、低温侧管道壁面与环境是绝热的. 高、低温侧管 道内为充分发展的层流(Hagen-poiseuille), 且为单相 流体. 流体定压比热容为 $c_{p}$, 运动粘度为 $v$, 密度为 $\rho$. 由于 $D_{1}$ 和 $D_{0}$ 管道直径不同, 可将图 1 所示的换热器 称为多尺度换热器.

换热器冷、热流体管道的总体积和换热器网络所 占的面积分别为

$$
V=\frac{2 \pi}{4}\left(2 D_{0}^{2} L_{0}+D_{1}^{2} L_{1}\right),
$$






View from above



图 1 矩形区域内 $\mathbf{T}$ 形多尺度换热器 ${ }^{[65]}$

$$
A=8 L_{0} L_{1} .
$$

设换热器网络管径比服从 Murry 定律, 即 $D_{1}=2^{1 / 3} D_{0}$. 在换热器管道的总体积 $V$ 和换热器网络所 占的面积 $A$ 给定的条件下, 由(4)和(5)式可得

$$
\begin{gathered}
D_{0}=\left[\frac{8 V^{2} \tilde{L}}{\pi^{2} A\left(1+2^{-1 / 3} \tilde{L}\right)^{2}}\right]^{1 / 4}, \\
L_{0}=\left(\frac{A}{8 \tilde{L}}\right)^{1 / 2},
\end{gathered}
$$

式中, $\tilde{L}=L_{1} / L_{0}$.

在换热器冷、热流体热容率相等的条件下, 其沿 程温差 $\Delta T$ 为常数 ${ }^{[22]}$. 冷、热流体进口温度 $T_{h, \text { in }}$ 和 $T_{c, \text { in }}$ 给定, 由热力学第一定律可知

$$
\left(U_{1} \pi D_{1} L_{1}+2 U_{0} \pi D_{0} L_{0}\right) \Delta T=\dot{m} c_{p}\left(T_{h, \text { in }}-T_{c, \text { in }}-\Delta T\right),
$$

式中, $U_{i}(i=0,1)$ 为忽略管内泥垢和管壁导热热阻的管 间总传热系数

$$
\frac{1}{U_{i}}=\frac{1}{h_{i}}+\frac{1}{h_{i}},
$$

式中, $h_{i}(i=0,1)$ 为单侧管内流体传热系数

$$
h_{i}=k N u_{i} / D_{i},
$$

式中, $k$ 为流体导热系数, $N u_{i}(i=0,1)$ 为努塞尔数. 在 管内层流流动条件下, $D_{0}$ 和 $D_{1}$ 管道内 $N u_{i}$ 值相差不大,
为简化计算, 假设各管道内的 $N u_{i}$ 近似相等 ${ }^{[65,72]}$ (记 为 $N u)$.

由(8) (10)式可得换热器冷、热流体的温差为

$$
\Delta T=\frac{2 M A^{1 / 2}\left(T_{h, \text { in }}-T_{c, \text { in }}\right)}{2 L_{0}+L_{1}+2 M A^{1 / 2}},
$$

式中, 无量纲质量流率 $M=\frac{\dot{m} c_{p}}{\pi k N u A^{1 / 2}}$. 由(3), (8) (11) 式可得换热器总换热率和䍉耗散率分别为

$$
\begin{gathered}
q=\left(U_{1} \pi D_{1} L_{1}+2 U_{0} \pi D_{0} L_{0}\right) \Delta T \\
=\frac{\pi k N u A^{1 / 2} M\left(2 L_{0}+L_{1}\right)\left(T_{h, \text { in }}-T_{c, \text { in }}\right)}{2 L_{0}+L_{1}+2 A^{1 / 2} M}, \\
\dot{E}_{v h \phi}=q \Delta T=\frac{2 \pi k N u A M^{2}\left(L_{1}+2 L_{0}\right)\left(T_{h, \text { in }}-T_{c, \text { in }}\right)^{2}}{\left(L_{1}+2 L_{0}+2 A^{1 / 2} M\right)^{2}} .
\end{gathered}
$$

根据(12)和(13)式的形式, 两式可分别无量纲化 为

$$
\begin{gathered}
\tilde{q}=\frac{q}{\pi k N u A^{1 / 2}\left(T_{h, \text { in }}-T_{c, \text { in }}\right)}=\frac{2^{1 / 2} M\left(2 \tilde{L}^{-1 / 2}+\tilde{L}^{1 / 2}\right)}{2^{1 / 2}\left(2 \tilde{L}^{-1 / 2}+\tilde{L}^{1 / 2}\right)+8 M}, \\
\tilde{\dot{E}}_{v h \phi}=\frac{\dot{E}_{v h \phi}}{\pi k N u A^{1 / 2}\left(T_{h, \text { in }}-T_{c, \text { in }}\right)^{2}} \\
=\frac{8 \cdot 2^{1 / 2} M^{2}\left(2 \tilde{L}^{-1 / 2}+\tilde{L}^{1 / 2}\right)}{\left[2^{1 / 2}\left(2 \tilde{L}^{-1 / 2}+\tilde{L}^{1 / 2}\right)+8 M\right]^{2}} .
\end{gathered}
$$

换热器冷、热流体所耗的无量纲总洜功率为

$$
\begin{aligned}
\tilde{W} & =W \frac{V^{2}}{4\left(k N u / c_{p}\right)^{2}(v / \rho) A^{5 / 2}} \\
& =2 \times \frac{128 \dot{m} v}{\pi \rho} \times\left(\dot{m}_{0} \frac{L_{0}}{D_{0}{ }^{4}}+\dot{m} \frac{L_{1}}{D_{1}^{4}}\right) \frac{V^{2}}{4\left(k N u / c_{p}\right)^{2}(v / \rho) A^{5 / 2}} \\
& =\frac{\pi^{3} M^{2}\left(2^{1 / 3}+\tilde{L}\right)^{3}}{2^{1 / 2} \tilde{L}^{3 / 2}} .
\end{aligned}
$$

陈永平等人 ${ }^{[68 ~ 71]}$ 建立了综合考虑换热器换热量 和总洜功的热有效性函数 (换热量与总业功的比值). 根据文献[68 71]对换热器热有效性的定义, 本文多 尺度换热器的热有效性 $\eta_{q W}$ 可定义为换热器无量纲换 热率与无量纲总泵功率之比

$$
\eta_{q W}=\frac{\tilde{q}}{\tilde{W}} .
$$

通过与换热器热有效性的定义类比, 多尺度换 热器的䍉耗散有效性 $\eta_{E W}$ 可定义为换热器无量纲熉耗 
散率与无量纲总原功率的比值

$$
\eta_{E W}=\frac{\tilde{\tilde{E}}_{v h \phi}}{\tilde{W}},
$$

式中, $\eta_{E W}$ 反映了换热器传热熕耗散率与总百功率的 折衷. (14) (16)式代入(17)和(18)式, 可得一级 $\mathrm{T}$ 形多 尺度换热器的热有效性 $\eta_{q W}$ 和积耗散有效性 $\eta_{E W}$ 分别 为

$$
\begin{aligned}
& \eta_{q W}=\frac{\tilde{q}}{\tilde{W}}=\frac{2 \tilde{L}(2+\tilde{L})}{\pi^{2} M\left(2^{1 / 3}+\tilde{L}\right)^{3}\left[2^{1 / 2}\left(2 \tilde{L}^{-1 / 2}+\tilde{L}^{1 / 2}\right)+8 M\right]}, \\
& \eta_{E W}=\frac{\tilde{E}_{v h \phi}}{\tilde{W}}=\frac{16 \tilde{L}(2+\tilde{L})}{\pi^{2}\left(2^{1 / 3}+\tilde{L}\right)^{3}\left[2^{1 / 2}\left(2 \tilde{L}^{-1 / 2}+\tilde{L}^{1 / 2}\right)+8 M\right]^{2}} .
\end{aligned}
$$

由(19)和(20)式可知, 当 $M$ 给定时, $\eta_{q W}$ 和 $\eta_{E W}$ 仅 与 $\tilde{L}$ 有关, 以 $\tilde{L}$ 为优化变量可对一级 $\mathrm{T}$ 形换热器进行 构形优化.

图 2 给出了不同无量纲质量流率 $M$ 下热有效性 和䍉耗散有效性最大的一级 $\mathrm{T}$ 形换热器最优构形比 较. 从图 2 中可以看出, 热有效性和沵耗散有效性最 大的最佳一级和单元级管长比 $\tilde{L}_{\mathrm{opt}, q W}$ 和 $\tilde{L}_{\mathrm{opt}, E W}$ 均随 $M$ 的增大而减小. 当 $M<<1$ 时, 热有效性和积耗散有效 性最大的最佳一级和单元级管长比分别为 $\tilde{L}_{\mathrm{opt}, E W}=$ 1.413 和 $\tilde{L}_{\mathrm{opt}, q W}=1.260$; 随着 $M$ 的增大, $\tilde{L}_{\mathrm{opt}, E W}$ 总是 大于 $\tilde{L}_{\mathrm{opt}, q W}$; 当 $M>>1$ 时, $\tilde{L}_{\mathrm{opt}, q W}$ 和 $\tilde{L}_{\mathrm{opt}, E W}$ 均保持

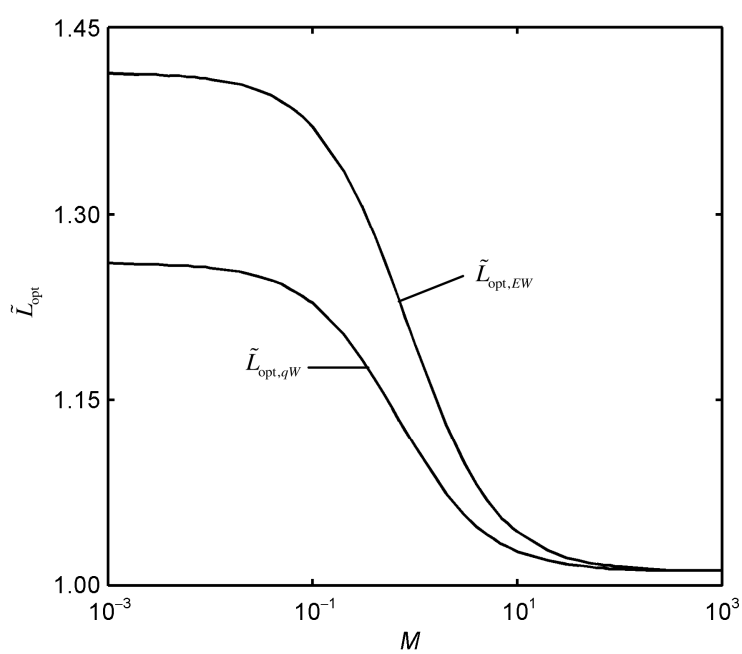

图 $2 \tilde{L}_{\mathrm{opt}}$ 与 $\boldsymbol{M}$ 的关系
1.012 不变. 由此可知, 在较小的冷、热流体质量流率 下, 热有效性和积耗散有效性最大的一级 $\mathrm{T}$ 形换热器 最优构形是明显不同的.

\section{4 多级 $\mathbf{H}$ 形换热器构形优化}

图 3 给出了矩形区域 $A$ 内 $(n=4)$ 级 $\mathrm{H}$ 形多尺度逆 流式换热器示意图 ${ }^{[65]}$. 高温流体 (质量流率 $\dot{m}_{n}=\dot{m}$ 、入 口温度 $T_{h, \text { in }}$ )从 $D_{n}$ 管道入口处进入, 在流经多级管道 (直径为 $D_{i}$ 、长度为 $L_{i}$ ) 的同时与对应的结构相同的低 温侧换热器管道换热, 最后从位于单元体中心的 $D_{0}$ 管道末端流出 (质量流率 $\dot{m}_{0}$ ). 低温流体与高温流体 为同一种流体, 在 $D_{0}$ 管道入口处, 其质量流率为 $\dot{m}_{0}$ 和入口温度为 $T_{c, \mathrm{in}}$. 多级 $\mathrm{H}$ 形换热器的尺寸和质量流 率关系分别为

$$
\begin{gathered}
L_{i}=2^{i / 2} L_{0}, D_{i}=2^{i / 3} D_{0}, \dot{m}_{i}=2^{i-n} \dot{m}, \\
n_{i}=2^{n-i},(i=0,1,2, \cdots, n),
\end{gathered}
$$

换热器冷、热流体管道总体积和换热器网络所占 的面积分别为

$$
\begin{aligned}
& V=2 \sum_{i=0}^{n} n_{i} L_{i} \frac{\pi D_{i}^{2}}{4}, \\
& A=2^{n}\left(2 L_{0} \times 2 L_{1}\right) .
\end{aligned}
$$

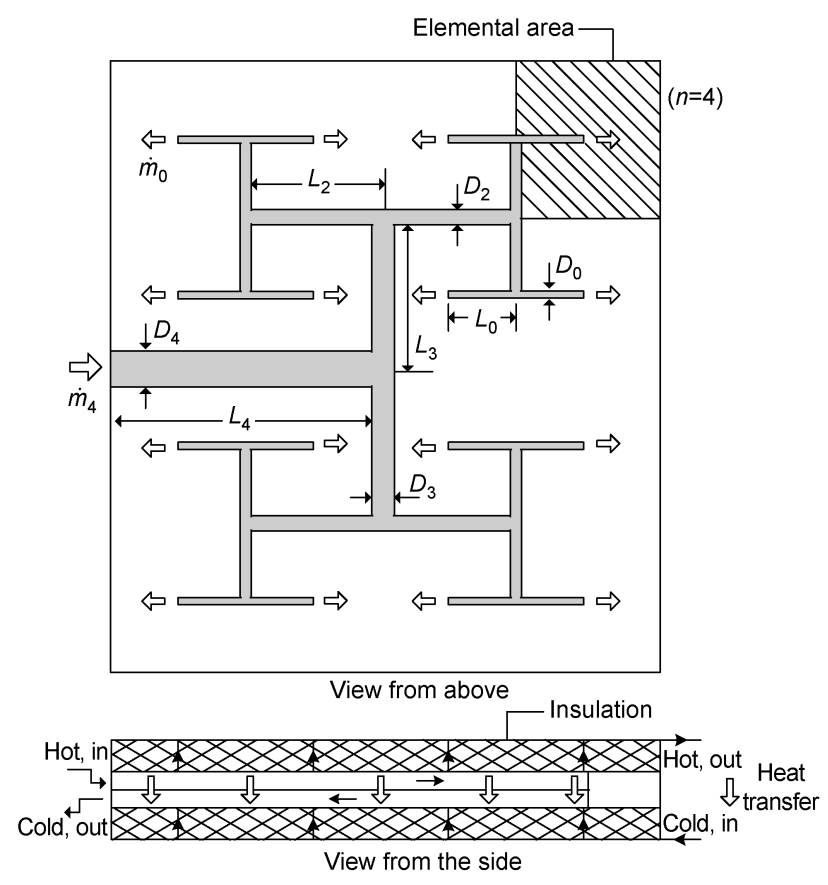

图 3 矩形区域内 $\mathbf{H}$ 形多尺度换热器 ${ }^{[65]}$ 
由(21) (23)式可得

$$
\begin{gathered}
D_{0}=\left[\frac{V\left(2^{1 / 6}-1\right)}{\pi A^{1 / 2}\left(2^{-\frac{25}{12}+\frac{2 n}{3}}-2^{-\frac{9}{4}+\frac{n}{2}}\right)}\right]^{1 / 2}, \\
L_{0}=2^{-\left(n+2+\frac{1}{2}\right) / 2} A^{1 / 2} .
\end{gathered}
$$

当换热器冷、热流体温差 $\Delta T$ 与位置无关时, 由 热力学第一定律可知

$$
\frac{\pi k N u \Delta T}{2} \sum_{i=0}^{n} n_{i} L_{i}=\dot{m} c_{p}\left(T_{h, \text { in }}-T_{c, \text { in }}-\Delta T\right) .
$$

将(21)和(25)式代入(26)式有

$$
\Delta T=\frac{4 M\left(2-2^{1 / 2}\right)\left(T_{h, \text { in }}-T_{c, \text { in }}\right)}{2^{\frac{3}{4}+\frac{n}{2}}-2^{1 / 4}+\left(8-2^{5 / 2}\right) M} .
$$

由(3), (21), (24), (25)和(27)式可得多级 $\mathrm{H}$ 形换热 器的无量纲总换热率、筫耗散率和总泵功率分别为

$$
\begin{gathered}
\tilde{q}=\frac{\pi k N u}{2} \Delta T \sum_{i=0}^{n} n_{i} L_{i} \frac{1}{\pi k N u A^{1 / 2}\left(T_{h, \text { in }}-T_{c, \text { in }}\right)} \\
=\frac{2^{1 / 4}\left[2^{(n+1) / 2}-1\right] M}{2^{1 / 4}\left[2^{(n+1) / 2}-1\right]+4 M\left(2-2^{1 / 2}\right)}, \\
\tilde{\dot{E}}_{v h \phi}=q \Delta T \frac{1}{\pi k N u A^{1 / 2}\left(T_{h, \text { in }}-T_{c, \text { in }}\right)^{2}} \\
=\frac{2^{9 / 4}\left(2-2^{1 / 2}\right)\left[2^{(n+1) / 2}-1\right] M^{2}}{\left[2^{1 / 4}\left(2^{n / 2+1 / 2}-1\right)+4 M\left(2-2^{1 / 2}\right)\right]^{2}}, \\
\tilde{W}=2 \times \frac{128 \dot{m} v}{\pi \rho} \sum_{i=0}^{n} \dot{m}_{i} \frac{L_{i}}{D_{i}^{4}} \frac{V^{2}}{4\left(k N u / c_{p}\right)^{2}(v / \rho) A^{5 / 2}} \\
=\frac{\pi^{3} M^{2} 2^{1 / 4-n / 2}\left[2^{(n+1) / 6}-1\right]^{3}}{\left(2^{1 / 6}-1\right)^{3}} .
\end{gathered}
$$

由(28) (30)式可得多级 $\mathrm{H}$ 形换热器的积耗散有 效性 $\eta_{E W}$ 为

$$
\begin{aligned}
\eta_{E W} & =\tilde{\dot{E}}_{v h \phi} / \tilde{W} \\
& =\frac{2^{2+\frac{n}{2}}\left(2^{1 / 6}-1\right)^{3}\left(2-2^{1 / 2}\right)\left[2^{(n+1) / 2}-1\right]}{\pi^{2}\left(2^{\frac{1+n}{6}}-1\right)^{3}\left\{2^{1 / 4}\left[2^{(n+1) / 2}-1\right]+4 M\left(2-2^{1 / 2}\right)\right\}^{2}} .
\end{aligned}
$$

由(31)式可知, 积耗散有效性 $\eta_{E W}$ 与 $M$ 和 $n$ 有关, 以 $M$ 和 $n$ 为变量可对多级 $\mathrm{H}$ 形换热器积耗散有效性 进行分析.

图 4 给出了不同换热器级数 $n$ 下积耗散有效性 $\eta_{E W}$ 与无量纲质量流率 $M$ 的关系. 从图 4 中可以看出, 给定换热器级数时, $\eta_{E W}$ 随 $M$ 的增大而减小, 且减小 幅度越来越大, 此时换热器炇耗散有效性越来越小. 当质量流率 $M<32.9$ 时, 积耗散有效性随换热器级数 的增加而减小; 在较大的质量流率下 (当 $n \leqslant 20$, 时, $M>508.1$ ), 䛈耗散有效性在 $n=4$ 时最小, 这是由于䍉 耗散有效性综合考虑了换热器的传热和流动性能, 使得炇耗散有效性与换热器级数之间不再是单调函 数; 当换热器级数大于 4 且级数逐渐增加时, 䍉耗散 有效性增大.

图 5 给出了不同管径比对多级 $\mathrm{H}$ 形换热器炽耗 散有效性 $\eta_{E W}$ 的影响. 当 $D_{i}=2^{i / 3} D_{0}(i=1,2, \cdots, n)$, 多级 $\mathrm{H}$ 形换热器管径比服从 Murry 定律; 当 $D_{i}=2^{i / 2} D_{0}(i=1$, $2, \cdots, n)$, 多级 $\mathrm{H}$ 形换热器各管道内流体流速相等; 当 $D_{i}=D_{0}(i=1,2, \cdots, n)$, 多级 $\mathrm{H}$ 形换热器各管道横截面积 相等, 此时为 $\mathrm{H}$ 形单尺度换热器. 从图 5 中可以看出, 当 $n=4$ 时, 管径比服从 Murry 定律的 $\mathrm{H}$ 形多尺度换热 器与各管道内流体流速相等的 $\mathrm{H}$ 形多尺度换热器相 比，其炇耗散有效性提高了 $36.54 \%$ 。管径比服从 Murry 定律的 $\mathrm{H}$ 形多尺度换热器与各管道横截面积 相等的 $\mathrm{H}$ 形单尺度换热器相比, 其䛈耗散有效性提高 了 198.94\%; 随着换热器级数的进一步增加, 其炽耗 散有效性的提高幅度更加显著. 由此可见, 管径比服

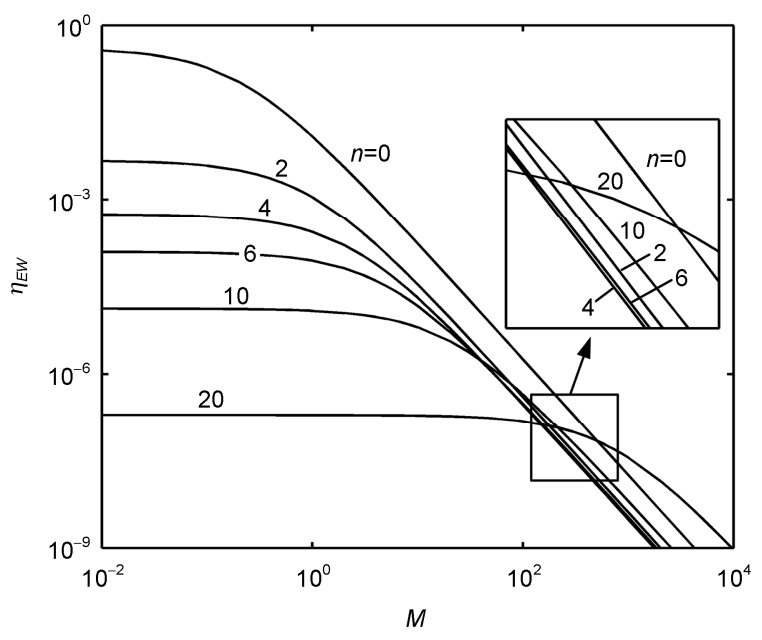

图 4 不同 $n$ 下 $\eta_{E W}$ 与 $M$ 关系 




图 5 不同管径比对 $\eta_{E W}$ 的影响

$1, D_{i}=2^{i / 3} D_{0} ; 2, D_{i}=2^{i / 3} D_{0} ; 3, D_{i}=D_{0}$

从 Murry 定律的 $\mathrm{H}$ 形多尺度换热器性能大大得到提 高; 事实上, 通过数值计算可进一步证明服从 Murry 定律的管径比是本文多尺度换热器的最优管径比; $\mathrm{H}$ 形多尺度换热器与 $\mathrm{H}$ 形单尺度换热器相比, 多尺度 换热器性能得到显著提高.

\section{5 管道表面积约束的 $\mathbf{H}$ 形换热器构形优化}

第 3 和 4 节中, 在给定换热器管道总体积的约束 条件下, 对多级 $\mathrm{H}$ 形换热器进行了构形优化. 在实际 换热器设计中, 管道换热面积也是一个重要的约束 条件. 本节将在给定换热器管道表面积的约束条件 下, 对多级 $\mathrm{H}$ 形换热器进行构形优化.

多级 $\mathrm{H}$ 形换热器冷、热流体管道的表面积为

$$
A_{a}=2 \sum_{i=0}^{n} \pi n_{i} L_{i} D_{i} .
$$

对于管道内充分发展的层流, 可设表面积约束 下的管道管径比为 ${ }^{[73]}$

$$
D_{i}=2^{2 i / 5} D_{0}(i=1,2, \cdots, n) .
$$

由(21), (23), (32)和(33)式可得

$$
D_{0}=\frac{2^{-13 / 20-2 n / 5}\left(2-2^{9 / 10}\right) A_{a}}{\pi A^{1 / 2}\left[2^{(n+1) / 10}-1\right]} .
$$

多级 $\mathrm{H}$ 形换热器冷、热流体所耗的无量纲总百 功率为

$$
\begin{aligned}
\tilde{W} & =W \frac{A_{a}{ }^{4}}{16\left(k N u / c_{p}\right)^{2}(v / \rho) A^{7 / 2}} \\
& =2 \times \frac{128 \dot{m} v}{\pi \rho} \sum_{i=0}^{n} \dot{m}_{i} \frac{L_{i}}{D_{i}^{4}} \frac{A_{a}{ }^{4}}{16\left(k N u / c_{p}\right)^{2}(v / \rho) A^{7 / 2}} \\
& =\frac{64 \times 2^{1 / 4}\left[2^{(n+1) / 10}-1\right]^{5} \pi^{5} M^{2}}{\left(2-2^{9 / 10}\right)^{5}} .
\end{aligned}
$$

由式(29)和(35)可得多级 H 形换热器的椥耗散有 效性 $\eta_{E W}$ 为

$$
\begin{aligned}
& \eta_{E W}=\tilde{E}_{v h \phi} / \tilde{W} \\
& =\frac{\left(2-2^{1 / 2}\right)\left(2-2^{9 / 10}\right)^{5}\left[2^{(n+1) / 2}-1\right]}{16 \pi^{4}\left[2^{(n+1) / 10}-1\right]^{5}\left[2^{1 / 4}\left(2^{\frac{1+n}{2}}-1\right)+4 M\left(2-2^{1 / 2}\right)\right]^{2}} .
\end{aligned}
$$

图 6 给出了管道表面积约束下换热器级数 $n$ 对 换热器炇耗散有效性 $\eta_{E W}$ 的影响. 从图 6 中可以看出, 给定换热器级数时, 管道表面积约束下的䍉耗散有效 性也随无量纲质量流率的增大而减小. 给定无量纲 质量流率时, 管道表面积约束下的䛈耗散有效性随换 热器级数的增加而减小, 但其变化幅度越来越小; 这 与较大质量流率下管道体积约束的焅耗散有效性与 换热器级数的特性关系是不同的.

图 7 给出了管道表面积约束下不同管径比对换 热器椥耗散有效性 $\eta_{E W}$ 的影响. 从图 7 中可以看出, 管径比服从 Murry 定律的 $\mathrm{H}$ 形多尺度换热器积耗散 有效性与各管道内流体流速相等的 $\mathrm{H}$ 形多尺度换热

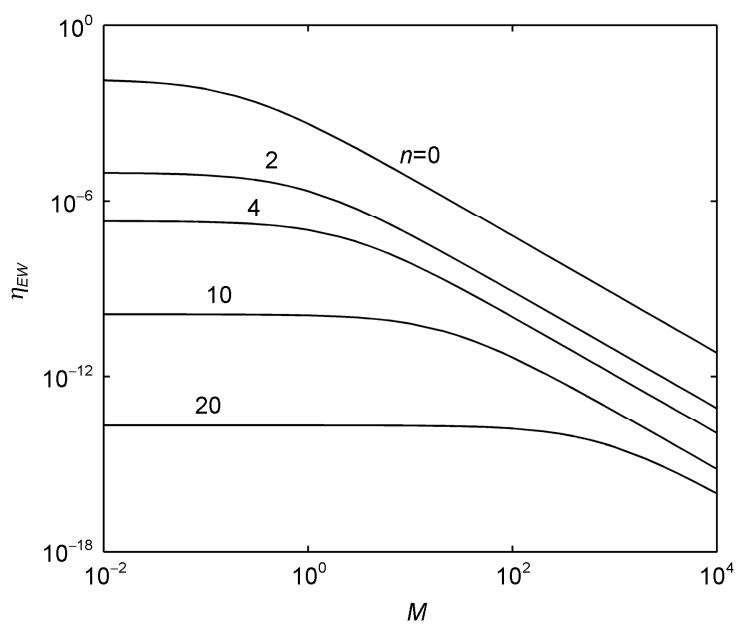

图 6 管道表面积约束下换热器级数对 $\eta_{E W}$ 的影响 


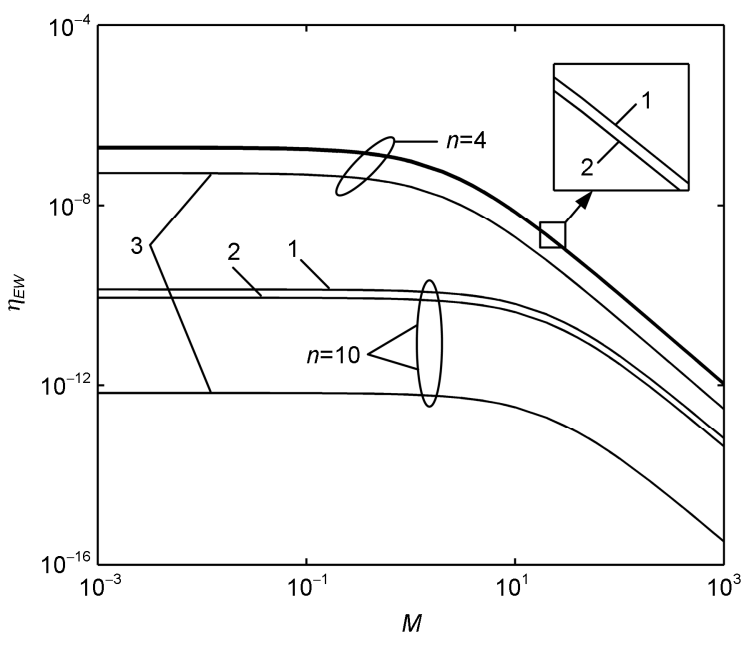

图 7 管道表面积约束下不同管径比对 $\boldsymbol{\eta}_{\boldsymbol{E}}$ 的影响 $1, D_{i}=2^{i / 3} D_{0} ; 2, D_{i}=2^{i / 3} D_{0} ; 3, D_{i}=D_{0}$

器枳耗散有效性相差不大. 管径比服从 Murry 定律的 $\mathrm{H}$ 形多尺度换热器与各管道横截面积相等的 $\mathrm{H}$ 形单 尺度换热器相比, 当 $n=4$ 时, 其换热器积耗散有效性 提高了 $283.91 \%$. 随着换热器级数的进一步增加, 其换 热器䍉耗散有效性的提高幅度更加显著. 由此可见, 在管道表面积约束条件下, $\mathrm{H}$ 形多尺度换热器与 $\mathrm{H}$ 形 单尺度换热器相比, 多尺度换热器性能仍然得到显 著提高.

\section{6 结论}

本文通过与换热器热有效性定义类比, 定义了 换热器的积耗散有效性(无量纲䍉耗散率与无量纲总 葲功率的之比). 并基于构形理论, 以积耗散有效性 最大为优化目标, 分别在换热器管道总体积 $V$ 和总表 面积 $A_{a}$ 一定的条件下, 对 $\mathrm{H}$ 形多尺度换热器进行了 构形优化, 得到了积耗散有效性最大的 $\mathrm{H}$ 形多尺度换 热器最优构形.
1) 在换热器管道总体积 $V$ 的条件下, 对于一级 $\mathrm{T}$ 形换热器, 在较小的冷、热流体质量流率下, 热有 效性和烍耗散有效性最大的一级 $\mathrm{H}$ 形换热器最优构 形是明显不同的.

2) 对于 $\mathrm{H}$ 形多尺度换热器, 给定换热器级数时, 䛈耗散有效性随 $M$ 的增大而减小，且减小幅度越来 越大, 此时换热器炇耗散有效性越来越小.

3) 当无量纲质量流率 $M<32.9$ 时, 积耗散有效性 随换热器级数的增加而减小; 在较大的无量纲质量 流率下 (当 $n \leqslant 20$, 时, $M>508.1$ ), 积耗散有效性在 $n=4$ 时最小, 当换热器级数大于 4 且级数逐渐增加时, 积 耗散有效性增大.

4) 当 $n=4$ 时, 管径比服从 Murry 定律的 $\mathrm{H}$ 形多 尺度换热器积耗散有效性比各管道内流体流速相等 的换热器椥耗散有效性提高了 $36.54 \%$, 比各管道横 截面积相等的换热器䍉耗散有效性提高了 $198.94 \%$. 由此可见, $\mathrm{H}$ 形多尺度换热器与 $\mathrm{H}$ 形单尺度换热器相 比, 多尺度换热器性能得到显著提高; 在管道表面积 约束条件下, 仍然可以得到此结论.

积耗散目标是热量传递不可逆性的度量, 在给 定换热器冷、热流体入口温度的条件下, 换热器椥耗 散最大时, 换热器传热性能达到最优, 但这种优化没 有考虑到换热器的流动性能. 积耗散有效性这个目标 克服了传统换热器优化中换热器流动阻力因素被“湮 没” 和换热器总原功率较大的缺点, 它综合考虑了换 热器的传热和流动性能, 体现了换热器传热椥耗散 率与总原功率的折衷. 此外, 本文假设换热器冷、热 流体相同, 当冷、热流体不同时, 在换热器冷、热流 体热容率相等且两者定压比热容相差很小的条件下 仍然可以采用本文方法对其性能进行研究. 本文基 于倁理论的换热器构形优化能对换热器的设计起到 重要的指导作用, 工程上对换热器进行优化设计时 可选择换热器椥耗散有效性最大时的构形设计方案.

\section{参考文献}

1 Bejan A. The concept of irreversibility in heat exchanger design: counterflow heat exchangers for gas-to-gas applications. Tran ASME J Heat Transfer Trans, 1977, 99(3): 374-380

2 Bejan A. Second law analysis in heat transfer. Energy, 1980, 5(8-9): 720-732

3 Bejan A. Entropy Generation through Heat and Fluid Flow. New York: Wiley, 1982

4 Bejan A. Entropy Generation Minimization. Boca Raton FL: CRC Press, 1996

5 Shah R K, Sekulić D P. 换热器设计技术. 程林, 译. 北京: 机械工业出版社, 2010

6 徐志明, 扬善让, 陈钟顾. 换热器最优参数的变分解法. 化工学报, 1995, 46(1): 75-80 
7 熊大䂀, 李志信, 过增元. 换热器的效能与熵产分析. 工程热物理学报, 1997, 18(1): 90-94

8 Hesselgreaves J E. Rationalisation of second law analysis of heat exchanger. Int J Heat Mass Transfer, 2000, 43(22): 4189-4204

9 Shah R K, Skiepko T. Entropy generation extremum and their relationship with heat exchanger effectiveness-number of transfer unit behavior for complex flow arrangements. Trans ASME J Heat Transfer, 2004, 126(6): 994-1002

10 Guo J, Cheng L, Xu M. Optimization design of shell-and-tube heat exchanger by entropy generation minimization and genetic algorithm. Appl Therm Engng, 2009, 29(14-15): 2954-2960

11 Guo J, Cheng L, Xu M. Multi-objective optimization of heat exchanger design by entropy generation minimization. Trans ASME J Heat Transfer, 2010, 132(8): 081801

12 Guo Z, Zhu H, Liang X. Entransy-A physical quantity describing heat transfer ability. Int J Heat Mass Transfer, 2007, 50(13/14): 2545-2556

13 李志信. 过增元. 对流传热优化的场协同理论. 北京: 科学出版社, 2010

14 过增元, 程新广, 夏再忠. 最小热量传递势容耗散原理及其在导热优化中的应用. 科学通报, 2003, 48(1): 21-25

15 韩光泽, 朱宏晔, 程新广, 等. 导热与弹性系统及导电的相似性. 工程热物理学报, 2005, 26(6): 1022-1024

16 韩光泽, 过增元. 导热能力损耗的机理及其数学表述. 中国电机工程学报, 2007, 27(17): 98-102

17 朱宏晔, 陈泽敬, 过增元. 炽耗散极值原理的电热模拟实验研究. 自然科学进展, 2007, 17(12): 1692-1698

18 陈林根. 聟理论及其应用的进展. 科学通报, 2012, 57(30): 2815-2835

19 柳雄斌, 过增元, 孟继安. 换热器中的煍耗散与热阻分析. 自然科学进展, 2008, 18(10): 1186-1190

20 柳雄斌, 过增元. 换热器性能分析新方法. 物理学报, 2009, 58(7): 4766-4771

21 Guo Z, Liu X, Tao W, et al. Effectiveness-thermal resistance method for heat exchanger design and analysis. Int J Heat Mass Transfer, 2010, 53(13-14): 2877-2884

22 宋伟明, 孟继安, 梁新刚, 等. 一维换热器中温差场均匀性原则的证明. 化工学报, 2008, 59(10): 2460-2464

23 夏少军, 陈林根, 孙丰瑞. 换热器炽耗散最小优化. 科学通报, 2009, 54(15): 2240-2246

24 郭江峰, 许明田, 程林. 换热器设计中的炽耗散均匀性原则. 中国科学: 技术科学, 2010, 40(6): 671-676

25 郭汇峰, 许明田, 程林. 换热量和换热面积给定时的炽耗散最小原则. 科学通报, 2010, 55(32): 4141-3146

26 柳雄斌, 孟继安, 过增元. 换热器参数优化中的熵产极值和炽耗散极值. 科学通报, 2008, 52(24): 3026-3029

27 Qian X, Li Z. Analysis of entransy dissipation in heat exchangers. Int J Therm Sci, 2011, 50(4): 608-614

28 Cheng X, Zhang Q, Liang X. Analyses of entransy dissipation, entropy generation and entransy-dissipation-based thermal resistance on heat exchanger optimization. Appl Therm Engng, 2012, 38: 31-39

29 郭江峰, 程林, 许明田. 欵耗散数及其应用. 科学通报, 2009, 54(19): 2998-3002

30 郭江峰, 许明田, 程林. 基于积耗散数最小的板翅式换热器优化设计. 工程热物理学报, 2011, 32(5): 827-831

31 李孟寻, 程林, 许明田. 积耗散理论在管壳式换热器优化设计中的应用. 工程热物理学报, 2010,31(7): 1189-1192

32 Chen L, Chen Q, Li Z, et al. Optimization for a heat exchanger couple based on the minimum thermal resistance principle. Int J Heat Mass Transfer, 2009, 52(21-22): 4778-4784

33 陈群, 吴晶, 王沫然, 等. 换热器组传热性能的优化原理比较. 科学通报, 2011, 56(1): 79-84

34 Qian X, Li Z, Li Z. Entransy-dissipation-based thermal resistance analysis of heat exchanger networks. Chin Sci Bull, 2011, 56(31): 3289-3295

35 Cheng X, Liang X. Computation of effectiveness of two-stream heat exchanger networks based on concepts of entropy generation, entransy dissipation and entransy-dissipation- based thermal resistance. Energy Convers Mgmt, 2012, 58: 163-170

$36 \mathrm{Xu} \mathrm{Y,} \mathrm{Chen} \mathrm{Q.} \mathrm{Minimization} \mathrm{of} \mathrm{mass} \mathrm{for} \mathrm{heat} \mathrm{exchanger} \mathrm{networks} \mathrm{in} \mathrm{spacecrafts} \mathrm{based} \mathrm{on} \mathrm{the} \mathrm{entransy} \mathrm{dissipation} \mathrm{theory.} \mathrm{Int} \mathrm{J} \mathrm{Heat} \mathrm{Mass}$ Transfer, 2012, 55(19-20): 5148-5156

37 许明田, 程林, 郭江峰. 积耗散理论在换热器设计中的应用. 工程热物理学报, 2009, 30(12): 2090-2092

38 李雪芳, 郭江峰, 许明田, 等. 换热器优化设计中最小积耗散方法. 科学通报, 2011, 56(11): 871-875

39 郭江峰, 许明田, 程林. 两流体换热器内粘性热对两流体积的影响. 中国科学: 技术科学, 2011, 41(5): 621-627

40 郭江峰, 许明田, 程林. 换热器内随温度变化的黏度对两流体啝的影响. 科学通报, 2011, 56(23): 1934-1939

41 Guo J, Xu M. The application of entransy dissipation theory in optimization design of heat exchanger. Appl Therm Engng, 2012, 36: $227-235$

42 魏曙睘, 陈林根, 孙丰瑞. 基于矩形单元体的以积耗散最小为目标的“体点”导热构形优化. 中国科学 $\mathrm{E}$ 辑：技术科学, 2009, 39(2): $278-285$

43 魏曙寰, 陈林根, 孙丰瑞. 以积耗散最小为目标的电磁体多学科构形优化. 中国科学 $\mathrm{E}$ 辑: 技术科学, 2009, 39(9): 1606-1613 
44 谢志辉, 陈林根, 孙丰瑞. 以烍耗散最小为目标的空腔几何构形优化. 中国科学 E 辑: 技术科学, 2009, 39(12): 1949-1957

45 谢志辉, 陈林根, 孙丰瑞. T 形腔炽耗散最小构形优化. 科学通报, 2009, 54(17): 2605-2612

46 魏曙睘, 陈林根, 孙丰瑞. 基于炽耗散率最小的离散和连续变截面导热通道构形优化. 中国科学: 技术科学, 2010, 40(10): 1189-1200

47 肖庆华，陈林根，孙丰瑞. 基于炽耗散率最小的“盘点”导热构形优化. 科学通报, 2010, 55(24): 2427-2437

48 肖庆华, 陈林根, 孙丰瑞. 基于欵耗散率最小的伞形柱状肋片构形优化. 中国科学：技术科学, 2011, 41(3): 365-373

49 肖庆华, 陈林根, 孙丰瑞. 基于欵耗散率和流阻最小的冷却流道构形优化. 中国科学: 技术科学, 2011, 41(2): 251-261

50 Chen L, Wei S, Sun F. Constructal entransy dissipation rate minimization of a disc. Int J Heat Mass Transfer, 2011, 54(1-3): 210-216

51 Wei S, Chen L, Sun F. Constructal entransy dissipation rate minimization of round tube heat exchanger cross-section. Int J Therm Sci, 2011, 50(7), 1285-1292

52 谢志辉, 陈林根, 孙丰瑞. $\mathrm{T}$ 形肋炽耗散率最小与最大热阻最小构形优化的比较研究. 中国科学: 技术科学, 2011, 41(7): 962-970

53 肖庆华, 陈林根, 孙丰瑞. 基于积耗散极值原理的蒸汽发生器构形优化. 中国科学: 技术科学, 2011, 41(8): 1090-1096

54 肖庆华, 陈林根, 孙丰瑞. 强迫对流换热冷却的产热体聟耗散率最小构形优化. 科学通报, 2011, 56(24): 2032-2039

55 冯辉君, 陈林根, 孙丰瑞. 基于炽耗散率最小的三维圆柱形单元体和微、纳米尺度下矩形、三角形单元体体点导热构形优化. 中国科 学: 技术科学, 2012, 42(3): 257-271

56 冯辉君, 陈林根, 孙丰瑞. 基于㵞耗散率最小的叶形肋片构形优化. 中国科学: 技术科学, 2012, 42(4): 456-466

57 Bejan A. Shape and Structure, from Engineering to Nature. Cambridge: Cambridge University Press, UK, 2000

58 Bejan A, Lorente S. Thermodynamic optimization of flow geometry in mechanical and civil engineering. J Non-Equilib Thermodyn, 2001, 26(4): 305-354

59 Bejan A, Lorente S. Constructal theory of generation of configuration in nature and engineering. J Appl Phys, 2006, 100(4): 041301

60 Bejan A, Merkx G (Editors). Constructal Theory of Social Dynamics. New York: Springer, 1 edition, 2007

61 Bejan A, Lorente S. Design with Constructal Theory. New Jersey: Wiley, 2008

62 Bejan A, Lorente S, Miguel A, Reis A H. Constructal Human Dynamics, Security \& Sustainability. Amsterdam: IOS Press, 2009

63 Bejan A, Zane P J. Design in Nature. New York: Doubleday, 2012

64 陈林根. 构形理论及其应用的研究进展. 中国科学: 技术科学, 2012, 42(5): 505-524

65 da Silva A K, Lorente S, Bejan A. Constructal multi-scale tree-shaped heat exchanger. J Appl Phys, 2004, 96(3): 1709-1718

66 Zimparov V D, da Silva A K, Bejan A. Constructal tree-shaped parallel flow heat exchangers. Int J Heat Mass Transfer, 2006, 49(23-24): 4558-4566

67 da Silva A K, Bejan A. Dendritic counterflow heat exchanger experiments. Int J Therm Sci, 2006, 45(9): 860-869

68 Chen Y, Cheng P. An experimental investigation on the thermal efficiency of fractal tree-like microchannel nets. Int Comm Heat Mass Transfer, 2005, 32(7): 931-938

69 张程宾, 陈永平, 杨迎春, 等. 构形树状小通道热沉的传热分析. 工程热物理学报, 2010, 31(5): 824-826

70 Chen Y, Zhang C, Shi M, et al. Thermal and hydrodynamic characteristics of constructal tree-shaped minichannel heat sink. AIChE J, 2010, 56(8): 2018-2029

71 Zhang C, Chen Y, Wu R, et al. Flow boiling in constructal tree-shaped minichannel network. Int J Heat Mass Transfer, 2011, 54(1-3): 202-209

72 杨世铭, 陶文铨. 传热学(第 4 版). 北京: 高等教育出版社, 2006

73 Bejan A, Rocha L A O, Lorente S. Thermodynamic optimization of geometry: T- and Y- shaped constructs of fluid streams. Int J Therm Sci, 2000, 39(9): 949-960 